\title{
Association of Depression With Increased Risk of Severe Hypoglycemic Episodes in Patients With Diabetes
}

\author{
Wayne J. Katon, $M D^{1}$ \\ Bessie A. Young, MD, MPH \\ Joan Russo, $P b D^{1}$ \\ Elizabeth H. B. Lin, MD, MPH \\ Paul Ciechanowski, MD, MPH ${ }^{1}$ \\ Evette J. Ludman, $P b D^{3}$ \\ Michael R. Von Korff, ScD ${ }^{3}$ \\ 'Department of Psychiatry, University \\ of Washington Medical School, Seattle, \\ Washington \\ ${ }^{2}$ Epidemiologic Research and Informa- \\ tion Center, Veterans Affairs Puget Sound \\ Health Care System, Kidney Research \\ Institute, University of Washington, Seattle, \\ Washington
}

${ }^{3}$ Group Health Research Institute, Seattle, Washington

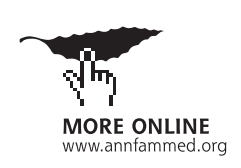

Conflicts of interest: authors report none.

\section{CORRESPONDING AUTHOR}

Wayne J. Katon, MD 1959 NE Pacific St Seattle, WA 98195-6560 wkaton@u.washington.edu

\begin{abstract}
PURPOSE Although psychosocial and clinical factors have been found to be associated with hypoglycemic episodes in patients with diabetes, few studies have examined the association of depression with severe hypoglycemic episodes. This study examined the prospective association of depression with risk of hypoglycemic episodes requiring either an emergency department visit or hospitalization.
\end{abstract}

METHODS In a longitudinal cohort study, a sample of 4,117 patients with diabetes enrolled between 2000 and 2002 were observed from 2005 to 2007. Meeting major depression criteria on the Patient Health Questionnaire-9 was the exposure of interest, and the outcome of interest was an International Classification of Disease, Ninth Revision code for a hypoglycemic episode requiring an emergency department visit or hospitalization. Proportional hazard models were used to analyze the association of baseline depression and risk of one or more severe hypoglycemic episodes. Poisson regression was used to determine whether depression status was associated with the number of hypoglycemic episodes.

RESULTS After adjusting for sociodemographic, clinical measures of diabetes severity, non-diabetes-related medical comorbidity, prior hypoglycemic episodes, and health risk behaviors, depressed compared with nondepressed patients who had diabetes had a significantly higher risk of a severe hypoglycemic episode (hazard ratio $=1.42,95 \% \mathrm{Cl}, 1.03-1.96$ ) and a greater number of hypoglycemic episodes (odds ratio $=1.34,95 \% \mathrm{Cl}, 1.03-1.74$ ).

CONCLUSION Depression was significantly associated with time to first severe hypoglycemic episode and number of hypoglycemic episodes. Research assessing whether recognition and effective treatment of depression among persons with diabetes prevents severe hypoglycemic episodes is needed.

Ann Fam Med 2013;11:245-250. doi:10.1370/afm.1501

\section{INTRODUCTION}

$\mathrm{R}$ eduction of blood glucose is an important goal of treatment in patients with diabetes and has been found to decrease risk of complications. A potential risk of treatment with glucose-lowering medications is hypoglycemia. Hypoglycemia may be caused by either excess endogenous insulin induced by insulin secretagogues or excess exogenous insulin associated with insulin treatment. ${ }^{1}$ Minor episodes of hypoglycemia are often corrected by patients with intake of glucose tablets or simple carbohydrate foods or liquids. More severe episodes of hypoglycemia may lead to loss of consciousness, trauma-related injuries, seizures, coma, myocardial infarction, cognitive impairment, and mortality. ${ }^{2}$ Approximately 1 in 4 emergency hospitalizations for adverse drug events in the United States have been found to be due to hypoglycemic reactions related to medications that lower glucose. ${ }^{3}$

Prior studies have found that hypoglycemic episodes may result from behavioral, physiologic, and therapeutic factors. ${ }^{4-6}$ The most common 
behavioral factors include poor adherence to self-care activities, such as lack of regular meals, inconsistent blood glucose monitoring, erratic use of glucoselowering medications, use of alcohol, or increases in exercise. ${ }^{6-8}$ Therapeutic and physiologic factors include older age, longer duration of treatment, medical comorbidities, diabetic complications (especially nephropathy), loss of residual insulin secretion, loss of awareness of hypoglycemia, and defects in glucagon responses to hypoglycemia. ${ }^{2,9-11}$

Although behavioral, physiologic, and therapeutic factors have been examined as causes of hypoglycemia, the authors are aware of only one study that examined the association of depression with severe hypoglycemic episodes in a population of adults with diabetes. ${ }^{12}$ This study found that depression increased risk of hypoglycemic episodes. The study had several limitations, however, including use of an unvalidated depression measure and that data on hypoglycemic episodes were from the year before depression ascertainment.

There are several important reasons to examine the impact of comorbid depression in patients with diabetes or risk of hypoglycemia. Major depression occurs in up to $18 \%$ of patients with diabetes ${ }^{13}$ and has been linked to lack of adherence to diet, exercise regimens, glucose monitoring, and key disease control medications. ${ }^{14}$ Comorbid depression has also been linked to an increased risk of poor glycemic control, microvascular and macrovascular complications, ${ }^{15}$ and dementia, ${ }^{16,17}$ which may further increase risk for hypoglycemic episodes.

In this prospective cohort study of patients with diabetes, we hypothesized that comorbid depression would be associated with time to the first severe hypoglycemic episode and number of severe hypoglycemic episodes over a 5 -year period.

\section{METHODS}

\section{Setting}

Group Health Cooperative is a mixed-model, capitated health plan serving more than 600,000 members in Washington State. Most Group Health members receive health care within an integrated health care system of approximately 30 primary care clinics in Western Washington.

\section{Study Cohort Selection}

The cohort for the Pathways Epidemiologic Follow-up Study ${ }^{18}$ was initially sampled between 2000 and 2002 from adults 18 years of age and older in the Group Health diabetes registry ${ }^{19}$ who received care from 9 primary care clinics in Western Washington. At 5 years after enrollment, surviving members of this ini- tial cohort were contacted again by either mail or telephone during 2005 to 2007. All consenting patients received a telephone interview and were asked for permission to review their medical records over the 5-year period.

Waiver of consent to review medical records was approved by the Group Health Human Subjects Committee for patients who had died during the 5 -year follow-up period, for patients unreachable by telephone, and for those physically unable to come to the telephone.

\section{Predictor of Interest}

The primary predictor of interest was major depression as determined by the Patient Health Questionnaire-9 (PHQ-9). ${ }^{20}$ The PHQ-9 is a self-report measure based on the American Psychiatric Association Diagnostic and Statistical Manual of Mental Disorders (Fourth Edition) (DSM-IV) criteria for major depression. ${ }^{20}$ The PHQ-9 contains the 9 DSM-IV major depressive symptoms, with each item scored on a 0 to 3 Likert scale. The criteria for major depression require at least 5 symptoms be endorsed more than one-half the time, including at least 1 of the cardinal symptoms of depressed mood or anhedonia. A recent systematic review found the PHQ-9 had a $77 \%$ sensitivity and $94 \%$ specificity for a diagnosis of major depression based on a structured psychiatric interview. ${ }^{21}$

\section{Potential Confounders}

Potential confounders (Supplemental Appendix 1, available at http://annfammed.org/content/11/3/245/ suppl/DC1) obtained from the mail survey and automated Group Health medical and laboratory records included patient characteristics (age, sex, education, and ethnic/racial status), clinical characteristics (any prior severe hypoglycemic episode within the 5 -year prebaseline period, diabetes duration, insulin use, RxRisk score, hypertension diagnosis, diabetes type (1 or 2), number of diabetes complications, body mass index, and health risk behaviors (smoking and physical activity from the Summary of Diabetes Self-Care Activities questionnaire). ${ }^{22}$ The diabetes complication measure has been shown to predict mortality and hospitalizations in the subsequent year. ${ }^{23}$ The RxRisk score is a computerized pharmacy measure of medical comorbidity that has been shown to be associated with subsequent medical costs and utilization. ${ }^{24}$

\section{Outcome of Interest}

Incident cases of emergency visits or hospitalizations for hypoglycemic episodes in the 5-year prebaseline interview and 5-year postbaseline interview were based on the following ICD-9 codes ascertained from the 
electronic medical record: 249.3, 249.8, 250.3, 250.8, 251.0, and 251.2. Because 249.3 and 250.3 include both diabetic ketoacidosis and hypoglycemic episodes, chart review for these codes was completed to exclude cases of ketoacidosis.

\section{Statistical Analyses}

Patients with comorbid depression and diabetes were compared with patients with diabetes alone on demographic, clinical, and health risk behaviors using $\chi^{2}$ analyses and $t$ tests. Cox survival analysis was used to estimate the statistical effect of depression upon days to first glycemic event. We first fit an unadjusted model containing only an indicator for depression.

Next, we added any severe hypoglycemic episode in the prebaseline 5-year period, demographic and clinical variables, and health risk behaviors to ascertain the statistical significance of depression in these models. To determine whether depression status was related to number of glycemic events, we used Poisson regressions. The outcome was the number of severe hypoglycemic events in the 5 -year postbaseline period. First, we fit an unadjusted model with just depression, then we subsequently added any severe hypoglycemic episode in the 5 years before the baseline, as well as demographic, clinical, and health risk variables, to the model while assessing depression for statistical significance.

Because treatment with insulin is associated with a greater risk of hypoglycemic episodes, effect modification of depression on risk of time to first hypoglycemic episode was evaluated by specifying an interaction between depression and treatment with insulin.

\section{RESULTS}

Among the 7,841 eligible patients with diabetes, 4,839 (61.7\%) returned the baseline mailed questionnaire, and the research team received permission to review medical records of 4,128 (85\%) (Figure 1). Of these patients 662 had died during the 5 -year follow-up period, 296 patients were unreachable by telephone, and 72 were physically unable to come to the telephone. Nine charts were unable to be located, leaving a sample of
4,119 patients included in these analyses. Differences between nonconsenting and consenting patients are listed in Supplemental Appendix 2 (http://annfammed.org/content/11/3/245/suppl/DC1).

Compared with patients who were not depressed, depressed patients were significantly more likely to be younger, female, unmarried, and to be treated with insulin despite similar duration of diabetes; they had more non-diabetes-related medical comorbidities, a higher number of diabetes complications, a higher body mass index and rates of smoking; and they were less physically active.

In the 5 -year prebaseline period, $8.1 \%$ of depressed patients with diabetes vs $3.1 \%$ of nondepressed control patients with diabetes experienced 1 or more severe hypoglycemic episodes (Table 1). Over the 5 -year follow-up period, $6.9 \%$ of patients reported at least 1 severe hypoglycemic episode. A total of $10.7 \%$ of

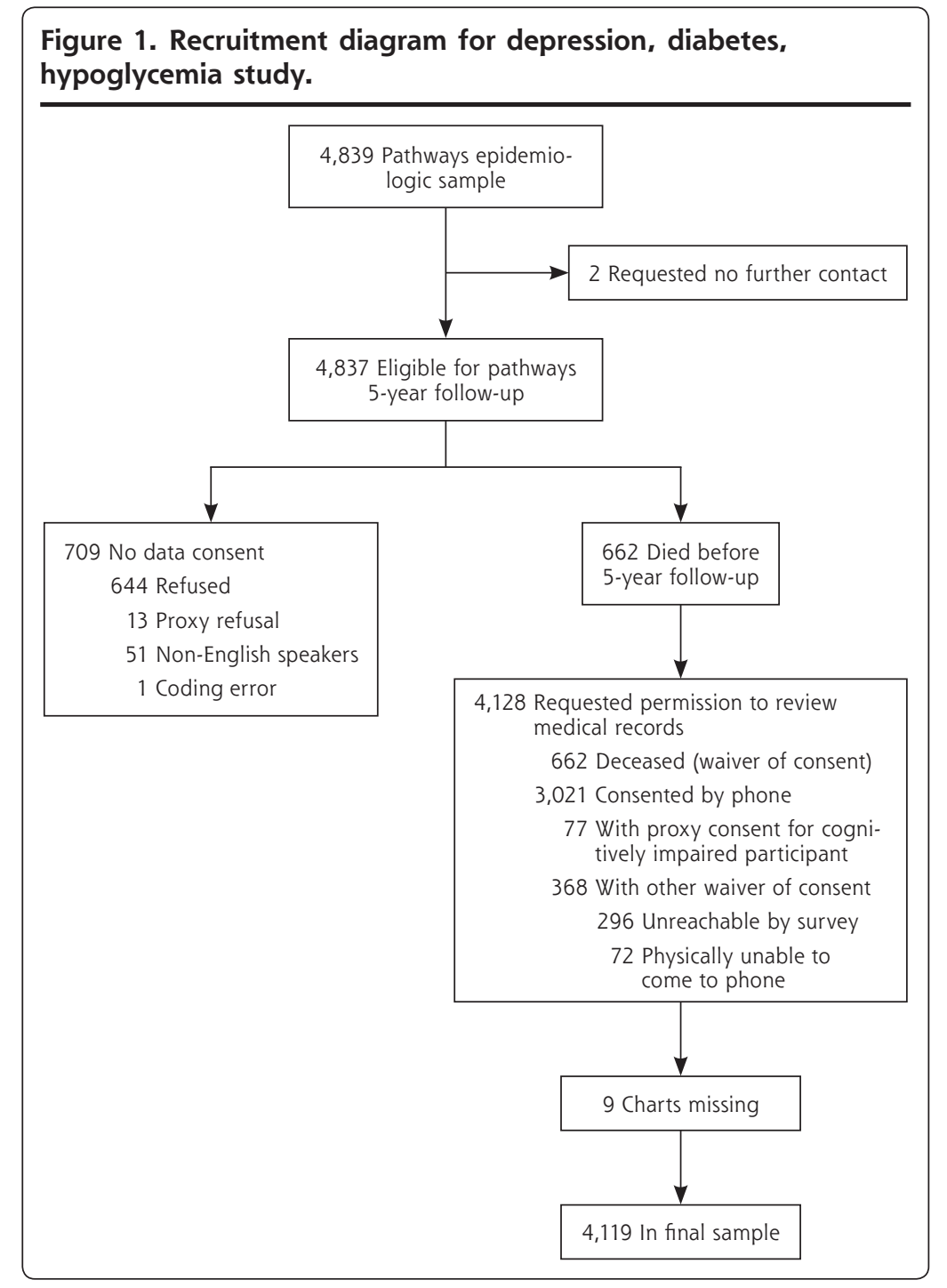


Table 1. Descriptive Statistics For the Study Sample $(\mathrm{N}=4,117)$

\begin{tabular}{|c|c|c|c|c|}
\hline Study Variable & Total & $\begin{array}{c}\text { Not Depressed } \\
n=3,622(88 \%)\end{array}$ & $\begin{array}{c}\text { Depressed } \\
n=495(12 \%)\end{array}$ & $P$ Value \\
\hline Any prebaseline hypoglycemic episode, ${ }^{\text {a }} \%$ (No.) & $3.7(153)$ & $3.1(113)$ & $8.1(40)$ & $<.001$ \\
\hline Any postbaseline hypoglycemic episode, b \% (No.) & $6.9(283)$ & $6.4(230)$ & $10.7(53)$ & $<.001$ \\
\hline Female, \% (No.) & $48.1(1,981)$ & $46.7(1,690)$ & $58.8(291)$ & $<.001$ \\
\hline Age, mean (SD), y & $63.4(13.4)$ & $64.0(13.3)$ & $59.4(13.8)$ & $<.001$ \\
\hline White, \% (No.) & $80.1(3,299)$ & $80.3(2,910)$ & $78.6(389)$ & .37 \\
\hline Married, \% (No.) & $65.4(2,693)$ & $66.8(2,418)$ & $55.6(275)$ & $<.001$ \\
\hline Some college ( $\geq 1$ year), \% (No.) & $76.2(3,134)$ & $76.6(2,774)$ & $72.4(360)$ & .06 \\
\hline Type 2 diabetes, \% (No.) & $95.6(3,933)$ & $95.4(3,457)$ & $96.2(476)$ & .47 \\
\hline Duration of diabetes, mean (SD), y & $9.6(9.4)$ & $9.6(9.6)$ & $9.6(8.3)$ & .87 \\
\hline Taking insulin, \% (No.) & $30.6(1,259)$ & $28.9(1,047)$ & $42.8(212)$ & $<.001$ \\
\hline RxRisk score, mean (SD)c & $3,133.7(2,441.0)$ & $3,093.0(2,386.3)$ & $3,431.4(2,793.5)$ & .01 \\
\hline Hypertension diagnosis, \% (No.) & $74.5(3,069)$ & $74.3(2,687)$ & $75.7(373)$ & .54 \\
\hline Diabetes complications, mean (SD), No. & $1.4(1.3)$ & $1.4(1.3)$ & $1.6(1.4)$ & $<.001$ \\
\hline Body mass index, mean (SD) & $31.5(7.3)$ & $31.1(6.8)$ & $34.8(9.3)$ & $<.001$ \\
\hline Current smoker, \% (No.) & $8.4(347)$ & $7.6(276)$ & $14.3(71)$ & $<.001$ \\
\hline Physical activity score, mean (SD) ${ }^{\mathrm{d}}$ & $2.7(2.2)$ & $2.8(2.2)$ & $1.9(1.4)$ & $<.001$ \\
\hline
\end{tabular}

depressed patients with diabetes had 1 or more severe hypoglycemic episodes, compared with $6.4 \%$ among nondepressed control patients (Table 1).

Unadjusted analyses (Table 2) showed that compared with nondepressed control patients, those with depression had a significantly shorter time to a first severe hypoglycemic episode and had a significantly higher number of severe hypoglycemic events. After adjusting for sociodemographic and clinical variables, prior hypoglycemic events in the 5 years before baseline and health risk behaviors, depressed patients with diabetes had a significantly shorter time to a first severe hypoglycemic episode and significantly more episodes (Table 2).

No evidence of effect modification of depression with treatment with insulin was found; thus, the risk of hypoglycemic episodes for depressed patients vs nondepressed patients was the same for those on insulin as those not on insulin.

\section{DISCUSSION}

In this prospective cohort study, comorbid depression in an adult population with diabetes was associated with an increased risk of time to a hypoglycemic episode requiring an emergency department visit or hospitalization and number of severe hypoglycemic episodes. This study is only the second of which the authors are aware that found depression was associated with increased risk of severe 
hypoglycemia episodes in a population-based sample of adults with diabetes. ${ }^{12} \mathrm{~A}$ previous study found that depression was associated with self-reported hypoglycemic episodes (which included both minor and more severe episodes) in 2,718 patients with type 2 diabetes. ${ }^{25}$ The increased risk of severe hypoglycemic episodes in patients with comorbid depression may be due to poor self-care or psychobiologic changes associated with depression. Patients with depression and diabetes, compared with those with diabetes alone, have been found to have poor adherence to diet, smoking cessation, and physical activity recommendations; poor blood glucose monitoring; and trouble taking key disease control classes of medications as prescribed. ${ }^{14,26}$ The increased risk of macrovascular and microvascular complications ${ }^{15}$ and dementia ${ }^{18,19}$ that has been found to be associated with comorbid major depression in patients with diabetes may also lead to weight loss. Weight loss may be associated with risk of hypoglycemia unless dosages of glucose-lowering medications are adjusted in a timely manner.

Depression may also lead to psychobiologic changes, such as dysregulation of the autonomic nervous system, higher cortisol levels, and increased inflammatory factors, ${ }^{26}$ all of which could lead to fluctuations in glycemic control. Based on poor glucose control, physicians may increase dosages of glucoselowering medications or augment with an additional glucose-lowering medication, which may subsequently increase risk of causing hypoglycemia.

Strengths of the study include that this study sample was a well-characterized population-based group of adults with diabetes that had detailed information on potential confounders. The stability of the population within Group Health and the extensive automated health utilization data allowed us to observe the cohort over a prolonged period to measure hypoglycemic episodes.

Limitations of these data include that only severe hypoglycemic episodes could be accurately measured $_{i}$ minor episodes not requiring emergency visits or hospitalization are much more common but could not be measured. Depression was measured only at 1 point $_{i}$ however, depression is often a chronic illness in patients with diabetes, with more than $70 \%$ with comorbid depression reporting they had been ill for longer than 2 years. ${ }^{27}$ The population was from 1 large health care system from 1 geographic region limiting generalizability. The observational nature of our data also limits interpretations of causality.

In this study, comorbid major depression was found to be a risk factor for severe hypoglycemic episodes in adults with diabetes. Research is needed to assess whether recognition and effective treatment of depres- sion among persons with diabetes prevents severe hypoglycemic episodes, as well as the increased risk of complications ${ }^{15}$ and mortality. ${ }^{28}$

To read or post commentaries in response to this article, see it online at http://www.annfammed.org/content/11/3/245.

Key words: depression; diabetes; hypoglycemia; mental health

Submitted May 31, 2012; submitted, revised, August 30, 2012; accepted September 28, 2012.

Acknowledgments: Supported by grants MH069741 (Katon) and MH073686 (Von Korff) from the Services Division of the National Institute of Mental Health.

\section{References}

1. Fanelli CG, Porcellati F, Pampanelli S, Bolli GB. Insulin therapy and hypoglycaemia: the size of the problem. Diabetes Metab Res Rev. 2004;20(Suppl 2):S32-S42.

2. Amiel SA, Dixon T, Mann R, Jameson K. Hypoglycaemia in type 2 diabetes. Diabet Med. 2008;25(3):245-254.

3. Budnitz DS, Lovegrove MC, Shehab N, Richards CL. Emergency hospitalizations for adverse drug events in older Americans. N Engl J Med. 2011;365(21):2002-2012.

4. Miller CD, Phillips LS, Ziemer DC, Gallina DL, Cook CB, El-Kebbi IM. Hypoglycemia in patients with type 2 diabetes mellitus. Arch Intern Med. 2001;161(13):1653-1659.

5. Ben-Ami H, Nagachandran P, Mendelson A, Edoute Y. Druginduced hypoglycemic coma in 102 diabetic patients. Arch Intern Med. 1999;159(3):281-284.

6. Banarer S, Cryer PE. Hypoglycemia in type 2 diabetes. [xii-xiii.]. Med Clin North Am. 2004;88(4):1107-1116, xii-xiii.

7. Sotiropoulos A, Skliros EA, Tountas C, Apostolou U, Peppas TA, Pappas SI. Risk factors for severe hypoglycaemia in type 2 diabetic patients admitted to hospital in Piraeus, Greece. East Mediterr Health J. 2005;11(3):485-489.

8. Nattrass M, Lauritzen T. Review of prandial glucose regulation with repaglinide: a solution to the problem of hypoglycaemia in the treatment of Type 2 diabetes? Int J Obes Relat Metab Disord. 2000; 24(Suppl 3):S21-S31.

9. UK Prospective Diabetes Study (UKPDS) Group. Intensive bloodglucose control with sulphonylureas or insulin compared with conventional treatment and risk of complications in patients with type 2 diabetes (UKPDS 33). Lancet. 1998;352(9131):837-853.

10. Shorr RI, Ray WA, Daugherty JR, Griffin MR. Incidence and risk factors for serious hypoglycemia in older persons using insulin or sulfonylureas. Arch Intern Med. 1997;157(15):1681-1686.

11. Davis TM, Brown SG, Jacobs IG, Bulsara M, Bruce DG, Davis WA. Determinants of severe hypoglycemia complicating type 2 diabetes: the Fremantle diabetes study. J Clin Endocrinol Metab. 2010; 95(5):2240-2247.

12. Honkasalo MT, Elonheimo OM, Sane T. Severe hypoglycaemia in drug-treated diabetic patients needs attention: a population-based study. Scand J Prim Health Care. 2011;29(3):165-170.

13. Ali S, Stone MA, Peters JL, Davies MJ, Khunti K. The prevalence of co-morbid depression in adults with Type 2 diabetes: a systematic review and meta-analysis. Diabet Med. 2006;23(11):1165-1173.

14. Lin EH, Katon W, Von Korff M, et al. Relationship of depression and diabetes self-care, medication adherence, and preventive care. Diabetes Care. 2004;27(9):2154-2160. 
15. Lin EH, Rutter CM, Katon W, et al. Depression and advanced complications of diabetes: a prospective cohort study. Diabetes Care. 2010;33(2):264-269.

16. Katon WJ, Lin EH, Williams LH, et al. Comorbid depression is associated with an increased risk of dementia diagnosis in patients with diabetes: a prospective cohort study. J Gen Intern Med. 2010; 25(5):423-429.

17. Katon W, Lyles CR, Parker MM, Karter AJ, Huang ES, Whitmer RA. Association of depression with increased risk of dementia in patients with type 2 diabetes: The Diabetes and Aging Study. Arch Gen Psychiatry. 2012;69(4)410-417.

18. Katon W, von Korff M, Ciechanowski $P$, et al. Behavioral and clinical factors associated with depression among individuals with diabetes. Diabetes Care. 2004;27(4):914-920.

19. McCulloch DK, Price MJ, Hindmarsh M, Wagner EH. A populationbased approach to diabetes management in a primary care setting: early results and lessons learned. Eff Clin Pract. 1998;1(1):12-22.

20. Kroenke K, Spitzer RL, Williams JB. The PHQ-9: validity of a brief depression severity measure. J Gen Intern Med. 2001;16(9):606-613.

21. Wittkampf KA, Naeije L, Schene AH, Huyser J, van Weert HC. Diagnostic accuracy of the mood module of the Patient Health Question naire: a systematic review. Gen Hosp Psychiatry. 2007;29(5):388-395.
22. Toobert DJ, Hampson SE, Glasgow RE. The summary of diabetes self-care activities measure: results from 7 studies and a revised scale. Diabetes Care. 2000;23(7):943-950.

23. Young BA, Lin $E$, Von Korff $M$, et al. Diabetes complications severity index and risk of mortality, hospitalization, and healthcare utilization. Am J Manag Care. 2008;14(1):15-23.

24. Fishman PA, Goodman MJ, Hornbrook MC, Meenan RT, Bachman DJ, O'Keeffe Rosetti MC. Risk adjustment using automated ambulatory pharmacy data: the RxRisk model. Med Care. 2003;41(1):84-99.

25. Green AJ, Fox KM, Grandy S; SHIELD Study Group. Self-reported hypoglycemia and impact on quality of life and depression among adults with type 2 diabetes mellitus. Diabetes Res Clin Pract. 2012; 96(3):313-318

26. Katon WJ. Epidemiology and treatment of depression in patients with chronic medical illness. Dialogues Clin Neurosci. 2011;13(1):7-23.

27. Katon WJ, Von Korff M, Lin EH, et al. The Pathways Study: a randomized trial of collaborative care in patients with diabetes and depression. Arch Gen Psychiatry. 2004;61(10):1042-1049.

28. Sullivan MD, O'Connor $\mathrm{P}$, Feeney $\mathrm{P}$, et al. Depression predicts all-cause mortality: epidemiological evaluation from the ACCORD HRQL substudy. Diabetes Care. 2012;35(8):1708-1715.

\section{CHANGE-OF-ADDRESS FORM FAMILY MEDICINE}

Please complete this form and mail to the following address or fax to Annals Circulation at 913-906-6080:

Annals of Family Medicine, Circulation Department, 11400 Tomahawk Creek Pkwy, Leawood, KS 66211-2680

Check if member of sponsoring organization: $\square$ AAFP $\square$ ABFM $\square$ STFM $\square$ ADFM

$\square$ AFMRD $\square$ NAPCRG $\square$ CFPC

ID number from label on your journal cover

OLD Information (Please print.)

\section{Name}

Company (if applicable)

Address (Street plus Apt or Ste)

City

Country

Telephone

E-Mail
NEW Information (Please print.)

\begin{tabular}{ll}
\hline Name \\
\hline Company (if applicable) & \\
\hline Address (Street plus Apt or Ste) & State \\
\hline City & Postal Code (9-digit ZIP for US) \\
\hline Country & Fax \\
\hline Telephone & \\
\hline E-Mail
\end{tabular}

